\title{
EDITORIAL
}

\section{POSITIVISMO, SUBJETIVISMO Y PRAGMATISMO}

Achig Balarezo David Ricardo ${ }^{1}$

La Comisión de Publicaciones de la Facultad de Ciencias Médicas invita a escribir en nuestra Revista; continuamos en el mejoramiento en la calidad de nuestras publicaciones cumpliendo con los procesos de reindexación en Latindex y Lilacs, desde este número contamos con el ISSN digital: 26616777.

VOLUMEN 37 | N 1 | ABRIL 2019

1. Universidad de Cuenca

\begin{tabular}{l} 
Editorial $\mid$ Editorial \\
\hline Correspondencia: \\
david.achigaucuenca.edu.ec \\
Dirección: \\
Nicanor Cobos 3-34 \\
Código Postal: \\
010207 \\
Teléfono: \\
099608840 \\
Cuenca - Ecuador
\end{tabular}

Bienvenidos para seguir construyendo este proceso de progreso para la Universidad, para visualizar y poner en marcha la investigación, para compartir esfuerzos y resultados, el quehacer científico y asistencial sanitario de la ciudad y la región [1].

Publicar los resultados de las investigaciones es un elemento fundamental del desarrollo científico de una comunidad; se trata de un espacio necesario para conocernos, para analizar la realidad, para transformarla; para contribuir en el registro de las condiciones de la salud de nuestra población. Asegurar más y mejor investigación [1], debatir y confrontar las formas en que se estructuran y modifican las evidencias y teorías [2], el uso de los instrumentos, la rigurosidad metodológica, la validez de los modelos es una preocupación y obligación de la Universidad [3,4], la Revista es uno de los medios.

La ciencia se alimenta y crece con paradigmas, Thomas Kuhn insistía en que el conocimiento científico no es el mero resultado de la acumulación de saberes, sino del cambio de paradigmas (modelos) [5], es decir la adopción de nuevos enfoques, conceptos y compromisos por la comunidad científica [5,6]; y que son producto de una construcción social e histórica [7].

Kuhn define un paradigma como un conjunto de creencias, valores y técnicas compartidos por una comunidad científica [6]; inscrito en un método y un referente teórico que guía el ciclo de la investigación [8].

Occidente y la ciencia heredera de la Grecia antigua, es el escenario donde el debate coloca los pilares y los fundamentos lógicos del método [9], Sócrates se valía de la mayéutica que consistía en sacar la verdad desde el interior del hombre; para Platón conocer es el simple acto de tomar conciencia de las ideas y mediante la dialéctica y el diálogo llegaba a conclusiones [10], Aristóteles enfatizaba en los métodos lógicos y prácticos para acceder al conocimiento y los principios fundamentales relacionados 
$[7,10]$ desarrollando así el método inductivo-deductivo [9].

En el siglo XII, Roberto Grosseteste y su discípulo Roger Bacon proponen el método experimental, mediante el cual es posible verificar las conclusiones alcanzadas por el método ideado en Aristóteles, hoy en día la experimentación es una característica definitoria de la ciencia [9].

Todo paradigma de investigación se apoya en un constructo filosófico que definirá el enfoque metodológico en donde interactúan tres elementos dinámicos: el objeto (fenómeno de estudio), el sujeto (investigador) y la praxis (campo práctico donde se produce la interrelación entre objeto y sujeto) [11].

\section{Paradigma positivista o lógico-positivista}

Herencia de la hipótesis-deducción [12], asume que existe un método mediante el cual el sujeto puede conocer de manera absoluta al objeto de conocimiento. Critica y rechaza argumentos metafísicos, descarta el empirismo sin comprobación. La realidad se puede conocer aplicando métodos cuantitativos [7].

El sujeto debe despojarse de sus sentimientos, emociones y subjetividad de tal modo que estudie el objeto "desde fuera"; el enfoque positivista pretende establecer leyes generales predecibles y controlables, es un único modelo para explicar la ciencia [10].

Predomina en la investigación en salud en un corte reduccionista, cultiva en exceso la observación [13], limitando la salud a la enfermedad, a lo individual; lo sano es únicamente lo empíricamente observable; el rigor científico depende de la aproximación a los órdenes inferiores de la realidad: genéticos y moleculares [13].

Las dimensiones cognitivas desde la que es posible estudiar el objeto que son: la de su ser (dimensión ontológica); la de su conceptualización (dimensión epistemológica); y la de sus formas de práctica (dimensión práxica o práctica). Las tres se desarrollan interdependientemente [14].

\section{Paradigma subjetivista}

Es intuitivo, el objeto se convierte en fenómeno a interpretar; contrario al modelo positivista, razona de lo general a lo particular, explica el objeto de estudio en su contexto, el sujeto como parte de una realidad o fenómeno para el análisis e interpretación. Su razonamiento [7]. 
Examina a un sujeto o una conciencia valorativa que a su vez será subjetivo si debe su existencia, su sentido o su validez a reacciones, ya sean fisiológicas o psicológicas, del sujeto que valora [13].

Esfenomenológica, enfatizando la experiencia subjetiva[15], cuestionándose la naturaleza de los fenómenos, procurando comprender los significados en que está inmersa la vida cotidiana de las personas u objetos, es decir, las interpretaciones que se dan a la experiencia vivida [15].

\section{Paradigma pragmático o instrumentalismo}

La teoría y su base instrumental son herramientas para organizar la descripción de los fenómenos y hacer inferencias; es aliada del racionalismo [13]. Considera a la ciencia como un conocimiento sobre el mundo de la naturaleza funcional que requiere instrumentos para producir teorías capaces de superar contrastes empíricos más exigentes, lo que las hace más fiables.

Las mejores teorías son las que han superado pruebas más fuertes y son útiles como guías fiables para conseguir los objetivos de la ciencia. La ciencia es un conocimiento sobre el mundo de naturaleza funcional, cuyo rechazo o sostenimiento viene determinado por la fecundidad en su descripción. El pragmatismo distingue los objetos reales del mundo y los teóricos (idealizaciones) de la ciencia, que describen a los otros. [13].

\section{Corolario}

El conocimiento científico en cualquier disciplina se produce en el movimiento entre sujeto y objeto en un campo de praxis; ninguna de los tres elementos define el método de manera absoluta.

Por tanto, al enfocar el objeto debemos apreciar que éste no existe como un “en sí" puro sin sujeto, ni tampoco existe un sujeto "en sí" puro sin objeto. El movimiento del conocimiento surge en la relación de los dos y esa relación se encuentra determinada por el movimiento práctico y momento histórico en el que se realiza [11]. 


\section{Referencias Bibliográficas}

1. Toledo E. La importancia de la investigación en salud. Salud en Tabasco. 2013;19[1]:1.

2. Santuario AA. Ciencia, conocimiento y sociedad. 2000;23.

3. Marzo SL. Generación endógena del conocimiento científico. Rev Publicando. 2017;10[1].

4. Breilh J. Metodología de la investigación en salud: determinación y evidencias. El método clínico fortalecido desde la epidemiología. 2003;21.

5. Marín-Gallego JD. Del concepto de paradigma e Thomas Kuhn a los paradigmas de las ciencias de la cultura. Magistro. 30 de junio de 2007;1[1]:73.

6. Lagarda MM. Los paradigmas científicos frente a los retos del significado axiológico en la educación. Estud Front. 2005;6:17.

7. Palacios-Espinoza E. Paradigmas de Investigación en salud. Rev Fac Cienc Médicas Univ Cuenca. 2014;32[2]:62-9.

8. Parreño A. Metodología de la investigación en salud [Internet]. Riobamba: ESPOCH; 2016 [citado 10 de marzo de 2019]. Disponible en: http://cimogsys.espoch.edu.ec/direccionpublicaciones/public/pdf/13/metodolog\%C3\%ADa\%20de\%20la\%20 investigaci\%C3\%B3n\%20en\%20salud.pdf

9. Roca Antonio J. Evolución de las relaciones entre la epistemología y la metodología de la investigación. Med Clin Barc. 1996;106:257-62.

10. Ramírez A. La teoría del conocimiento en investigación científica: una visión actual. An Fac Med. 2012;70[3]:217.

11. Breilh J. La determinación social de la salud como herramienta de transformación hacia una nueva salud pública [salud colectiva]. 2013;31:15.

12. Martinez Godínez VLM. Paradigmas de investigación, 2003, consulta en http://www.pics.uson.mx/wp-content/uploads/2013/10/7_ Paradigmas_de_investigacion_2013.pdf

13. Vázquez Á. Acevedo JA. Manassero MA. Cuatro paradigmas básicos sobre la naturaleza de la ciencia. Argumentos de Razón Técnica, 2001(4):135-176.

14. Breilh J. La epidemiología crítica: una nueva forma de mirar la salud en el espacio urbano. Salud Colect. 2 de abril de 2010;6[1]:83.

15. Dois A. Epistemología, Metodología de Investigación y Enfermería / Epistemology, Methodology of Research and Nursing. Horiz Enfermeria. 2008;19[1]:89-93. 